Analytical Methods

\title{
FTIR-ATR spectroscopy applied to quality control of grape-derived spirits
}

\author{
Ofélia Anjos ${ }^{\mathrm{a}, \mathrm{b}, *}$, António J.A. Santos ${ }^{\mathrm{b}}$, Letícia M. Estevinho ${ }^{\mathrm{c}}$, Ilda Caldeira ${ }^{\mathrm{d}, \mathrm{e}}$ \\ a Instituto Politécnico de Castelo Branco, Apartado 119, 6001-909 Castelo Branco, Portugal \\ ${ }^{\mathrm{b}}$ Centro de Estudos Florestais, Instituto Superior de Agronomia, Universidade de Lisboa, 1349-017 Lisboa, Portugal

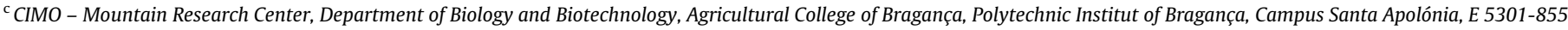 \\ Bragança, Portugal

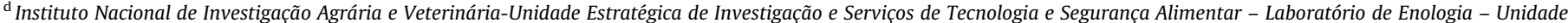 \\ de Investigação de Viticultura e Enologia, Dois Portos, Quinta da Almoínha, 2565-191 Dois Portos, Portugal \\ ${ }^{\mathrm{e}}$ ICAAM - Instituto de Ciências Agrárias e Ambientais Mediterrânicas, Universidade de Évora, Pólo da Mitra, Apartado 94, 7002-554 Évora, Portugal
}

\section{A R T I C L E I N F O}

\section{Article history:}

Received 28 September 2015

Received in revised form 14 February 2016

Accepted 20 February 2016

Available online 23 February 2016

\section{Keywords}

Methanol

Alcoholic strength

Fusel alcohols

Grape-derived spirits

Fourier transform infrared spectroscopy

Attenuated total reflectance

\begin{abstract}
A B S T R A C T
The Fourier transform infrared (FTIR) spectroscopic method with attenuated total reflectance (ATR) was used for predicting the alcoholic strength, the methanol, acetaldehyde and fusel alcohols content of grape-derived spirits. FTIR-ATR spectrum in the mid-IR region $\left(4000-400 \mathrm{~cm}^{-1}\right)$ was used for the quantitative estimation by applying partial least square (PLS) regression models and the results were correlated with those obtained from reference methods.

In the developed method, a cross-validation with $50 \%$ of the samples was used for PLS analysis along with a validation test set with $50 \%$ of the remaining samples. Good correlation models with a great accuracy were obtained for methanol $\left(r^{2}=99.4 ; \operatorname{RPD}=12.8\right)$, alcoholic strength $\left(r^{2}=97.2 ; \mathrm{RPD}=6.0\right)$, acetaldehyde $\left(r^{2}=98.2\right.$; RPD = 7.5) and fusel alcohols ( $r^{2}$ from 97.4 to 94.1; RPD from 6.2 to 4.1).

These results corroborate the hypothesis that FTIR-ATR is a useful technique for the quality control of grape-derived spirits, whose practical application may improve the efficiency and quickness of the current laboratory analysis.
\end{abstract}

(c) 2016 Elsevier Ltd. All rights reserved.

\section{Introduction}

The grape-derived spirits comprise the grape marc and the wine spirits, which are obtained respectively by distilling fermented grape pomace and wine. Prior to consumption, wine spirit must remain in wooden barrels for a minimum of six months, a process called maturation or ageing, after which it is labelled as brandy. On the other hand, the grape marc spirit can be consumed with or without that ageing process (EC No 110/2008). These alcoholic beverages are mainly composed of not only ethanol and water, but also several minor volatile compounds such as alcohols, acids, esters and other compounds that derive from the raw materials (wine and/or grape pomace), the fermentation and/or the distillation processes (Fotakis, Kokkotou, Zoumpoulakis, \& Zervou, 2013; Quady, Quady, \& Guymon, 1973).

The most plentiful volatile compounds in these distilled beverages are the fusel alcohols, the fatty acid esters together with

\footnotetext{
* Corresponding author at: Instituto Politécnico de Castelo Branco, Apartado 119, 6001-909 Castelo Branco, Portugal.

E-mail address: ofelia@ipcb.pt (O. Anjos).
}

acetaldehyde and methanol (Nykänen \& Nykänen, 1991). Fusel alcohols, also known as higher alcohols, are characteristic compounds of alcoholic beverages produced during the alcoholic fermentation and some of them are key flavour compounds (Caldeira, Anjos, Portal, Belchior, \& Canas, 2010). Among those, the more frequent are 1-propanol, 1-butanol, 2-butanol, 2-methyl-1-propanol (isobutanol), 2-methyl-1-butanol (amyl alcohol) and 3-methyl-1-butanol (isoamyl alcohols) (Nykänen \& Nykänen, 1991; Swiegers, Bartowsky, Henschke, \& Pretorius, 2005). The European Regulation EC No 110/2008 sets minimum levels of volatile compounds, other than ethanol and methanol, for several spirit drinks (rum, fruit spirits, mark spirit, wine spirit etc.). Further for grape marc spirit and wine spirit this minimum is, respectively, 140 and $125 \mathrm{~g} / \mathrm{hl}$ of pure alcohol.

It is important to state that some constituents of alcoholic beverages are regarded as possible determinants of toxicity, namely acetaldehyde (Linderborg, Joly, Visapää, \& Salaspuro, 2008). In spite of this, methanol and ethanol have been reported as the most hazardous compounds to health (Wiberg, Trenholm, \& Coldwell, 1970). 
Indeed, the methanol toxicity, which is well documented (Siu, Shapiro, Wiley, \& Wells, 2013), turns out from an excessive intake due to the hepatic transformation of methanol into formaldehyde and then into formate that predominantly affects the nervous system (Hantson, 2006). Therefore, to ensure the health of consumers, the maximum methanol concentration in grape marc spirit ( 1000 grams per hectolitre of $100 \%$ vol. alcohol) and wine spirit or brandy ( 200 grams per hectolitre of $100 \%$ vol. alcohol) is controlled by the Regulation EC No 110/2008. Concerning the alcoholic strength, it is an important parameter for production monitoring, quality control and labelling.

Methanol, ethyl acetate, acetaldehyde and fusel alcohols are usually quantified using gas chromatography (GC) equipment coupled to a flame ionisation detector (FID) (OIV, 2014). However, this technique is relatively time-consuming, requiring an entire day for the $c$ analysis of one spirit sample and requires expensive equipment consumables and some reagents likewise expensive and some of them are not environmentally friendly. In this context, the promising results obtained with infrared (IR) spectroscopic techniques appear as an important alternative for the quality control of alcoholic beverages (Lachenmeier, 2007; Workman \& Weyer, 2007).

Infrared spectroscopy based methods are very useful for the analysis of grapes' and wines' compositions due their versatility, efficiency and cost effectiveness, fast and non-invasiveness characteristics (Bauer et al., 2008). The use of ATR apparatus is advantageous due to the small volume of sample required, reduced preparation time, simplicity of instrument operation, data reproducibility and speed of analysis. Several applications of Fourier transform infrared spectroscopy (FTIR) using different spectral regions combined with multivariate data analysis have demonstrated promising results for some wine and grape analytical determinations, such as ethanol strength, dry extract, volatile acidity, glucose and fructose (Cocciardi, Ismail, \& Sedman, 2005; Lachenmeier, 2007; Lachenmeier, Richling, López, Frank, \& Schreier, 2005; Nagarajan, Gupta, Mehrotra, \& Bajaj, 2006; Nieuwoudt, Prior, Pretorius, Manley, \& Bauer, 2004; Tarantilis, Troianou, Pappas, Kotseridis, \& Polissiou, 2008).

The infrared spectroscopy techniques have been also applied in food authentication studies that report its important potential in ensuring the authenticity of spirit drinks (Lachenmeier, 2007; Palma, 2002; Pontes et al., 2006). In addition, it has recently been used in the control of honeys' sugar concentration (Anjos, Campos, Ruiz, \& Antunes, 2015) and in olive oil characterisation (Gouvinhas, de Almeida, Carvalho, Machado, \& Barros, 2015). Despite the increasing interest and the recent developments, few studies focus on the use of FTIR-ATR for the quality control of grape-derived distillates (grape marc spirits, wine spirits and brandies).

In this context, this study aims to evaluate the application of FTIR-ATR spectroscopy technique in combination with partial least squares (PLSs) algorithm in the quantification of alcoholic strength, methanol, acetaldehyde and fusel alcohols in grape-derived spirits.

\section{Material and methods}

\subsection{Samples}

A group of 166 grape derived spirits delivered to the Enology Laboratory of INIAV-Dois Portos were used for developing calibrating models, even though the determination of the alcoholic strength or fusel alcohols had not been required by the producers for all these samples.

The samples were produced in different distilleries in Portugal or were from retail trade. They were analysed using the reference methods, as well as by acquiring the IR spectrum in the FTIR-ATR equipment.
The wide number of analytical determinations and the wide range of samples (grape-derived spirits from different brands, different years and different production technologies) were allowed to improve the quickness of the analysis, which plays a key role in a quality control laboratory.

\subsection{Standards and chemicals}

Ethanol [CAS $N^{\circ}$ 64-17-5; purity $\geqslant 99.9$ ] and methanol for GCFID [CAS $\mathrm{N}^{\circ} 67-56-1$; purity $\geqslant 99.9 \%$ ] were purchased from Merck (Darmstadt, Germany). Ethyl acetate [CAS $\mathrm{N}^{\circ}$ 141-78-6; purity $\geqslant 99.8 \%$ ] was purchased from Riedel-de-Haen (Seelze, Germany), 2-methyl-1-butanol [CAS №34713-94-5; purity $\geqslant 98 \%$ ] 3methyl-1-butanol [CAS $\mathrm{N}^{\circ} 123-51-3$; purity $\geqslant 98.5 \%$ ], 1-butanol [CAS $\mathrm{N}^{\circ} 71-36-3$; purity $\geqslant 99.5 \%$ ], 2-methyl-1-propanol [CAS $\mathrm{N}^{\circ}$ 78-83-1; purity $\geqslant 99.5 \%$ ], 1-propanol [CAS $\mathrm{N}^{\circ}$ 71-23-8; purity $\geqslant 99.5 \%$ ], 2-butanol [CAS $\mathrm{N}^{\circ} 78-92-2$; purity $\geqslant 99.5 \%$ ] and acetaldehyde [CAS $\mathrm{N}^{\circ} 75-07-0$; purity $\geqslant 99.5 \%$ ] were purchased from Fluka (Buchs, Switzerland). The internal standard for GCFID, 4-methyl-2-pentanol [CAS N ${ }^{\circ} 108-11-2$; purity $\geqslant 98$ ] was purchased from Aldrich, supplied by Sigma-Aldrich (Zwijndrecht, Netherlands). Distilled water was used to prepare the hydro alcoholic solutions.

\subsection{Analytical reference procedures of methanol, ethyl acetate, acetaldehyde, fusel alcohols and alcoholic strength quantification}

Alcoholic strength was determined by the distillation of $250 \mathrm{~mL}$ of each spirit sample, followed by the determination of alcohol content on the distillate using an electronic densimeter (DMA5000, Antoon Paar) (OIV, 2014). All the results, obtained in duplicate, are presented as volumetric percentage of ethanol in the beverage.

For methanol, ethyl acetate, acetaldehyde and fusel alcohols quantification, the samples were analysed by GC-FID by direct injection of the spirit drink or by the injection of the distillate, obtained in the alcohol strength determination.

GC-FID analysis was carried out using a Focus GC gas chromatograph (Thermo Scientific, USA) equipped with a flame ionisation detector-FID $\left(250^{\circ} \mathrm{C}\right)$ and a fused silica capillary column of polyethylene glycol (DB-WAX, JW Scientific, Folsom, CA, USA), $60 \mathrm{~m}$ length, $0.32 \mathrm{~mm}$ i.d., $0.25 \mu \mathrm{m}$ film thickness, using the conditions previously described and validated (Luís, Mota, Anjos, \& Caldeira, 2011). Hydrogen was the carrier gas used $\left(3.40 \mathrm{~cm}^{3} \mathrm{~min}^{-1}\right)$. The samples were injected $(\sim 1 \mu \mathrm{L})$ on the injector $\left(200^{\circ} \mathrm{C}\right.$ ) in split mode (split ratio 1:6). The oven temperature programme was: $35^{\circ} \mathrm{C}$ (for $8 \mathrm{~min}$ ), then increased at $10^{\circ} \mathrm{C} \mathrm{min}-1$ to $200{ }^{\circ} \mathrm{C}$ and held at this temperature for a further 9 min (Luís et al., 2011).

The quantification was done through the analysis, under the same conditions, of hydroalcoholic standard solutions containing known amounts of the volatile compounds.

The volatile compound concentrations are expressed as $\mathrm{g} / \mathrm{hL}$ of pure alcohol (P.A.) (using the alcohol strength results) in order to verify the compliance with regulatory requirements (EC $\mathrm{N}^{\circ}$ 110/2008). All parameters were analysed in duplicate.

\subsection{FTIR-ATR equipment}

The FTIR-ATR spectra of the sample spirits were acquired in a period of time not higher than one month after the analysis with the reference methods. The samples were stored in the cellar of INIAV at Dois Portos, well closed in the bottles at a temperature approximately of $18^{\circ} \mathrm{C}$.

FTIR-ATR spectra of all samples were acquired with a Bruker FTIR spectrometer (Alpha) with a resolution of $4 \mathrm{~cm}^{-1}$ in the 
wavelength region $4000-400 \mathrm{~cm}^{-1}$, using a diamond single reflection attenuated total reflectance (ATR) device and a zero filling factor of 2. A duplicate spectra per sample (using two different aliquots from the same sample) was obtained with 32 scans per spectrum and the average for each sample was calculated automatically with the OPUS software.

A portion of samples was used to ensure that the ATR crystal is completely covered. The samples used were directly collected from the bottle without any kind of pre-treatment.

A background measurement was made before each ten-sample analysing using air as background. The result is referred to as a Power Spectrum where the signal intensity is distributed for each wavelength.

ATR crystal was carefully cleaned before and between each analysis firstly, with MilliQ water (at room temperature) and then with isopropanol and if necessary, the ATR crystal was dried with soft tissue paper.

The spectrums were collected in a constant room temperature of $20^{\circ} \mathrm{C}$.

\subsection{Data analysis}

Firstly, all abnormal spectra collected with FTIR-ATR, which could result either from incorrect sampling or local variation of air room temperature, were eliminated. As such, the number of samples used on the methanol content determination differed from the number used for alcoholic strength determination.

Then, the acquired spectral data were analysed in order to search correlations with GC-FID results. PLS regression was done using OPUS/Quant 2-A software (version 7.5.18 BRUKER). This regression is based on the spectral decomposition in which the original variables are replaced by new variables, which are linear combinations of the original ones.

The data were randomly split into two groups (Set $1-50 \%$ samples and Set 2 - the remaining 50\% samples) by means of principal component analysis. Each set was used for cross-validation (CV) and test set validation (TS), with Set 1 as CV and Set 2 as TS, and then the other way round, to evaluate if the model statistics were identical, or at least very similar (Santos et al., 2012).
Besides the raw spectra, also pre-processed spectra with six methods (multiplicative scatter correction - MSC, vector normalisation - VecNor, minimum-maximum normalisation - MinMax, straight line elimination - SLS, first derivative - 1stDer and second derivative - 2ndDer) were used for PLS analysis. Additionally, combinations of the first derivation with multiplicative scattering correction and straight line subtraction (1stDer + MSC and 1stDer + SLS) were also tested.

Usually, prior to multivariate calibration it is necessary to apply appropriate pre-processing in order to minimise physical effects. Indeed, data pre-treatment was performed to eliminate or minimise variability unrelated to the measured properties to better modelled pertinent changes than can be detected without pre-treatment (Rinnan, van den Berg, \& Engelsen, 2009).

The different pre-treatment tested are characterised by:

Multiplicative scatter correction, that performs a linear transformation of each spectrum with the aim of best matching the mean spectrum of the whole set;

Vector normalisation, which normalises a spectrum firstly by calculating the average intensity value and then subtracting this value from the spectrum. Afterwards, the sum of the squared intensities is calculated and the spectrum is divided by the square root of this sum;

Minimum-maximum normalisation that first subtracts a linear offset and then sets the $y$-maximum to a value of 2 by multiplication with a constant;

Straight line elimination, that fits a straight line to the spectrum and subtracts it;

First derivative, used to remove additive and multiplicative effects, first derivative removes the baseline;

Second derivative, which is similar to the first derivative, but removes both baseline and linear trend.

For all models, a PLS regression was done by means of full crossvalidation with one sample omitted, in order to obtain a significant number of rank (PLS components) according to the previously proposed methodology (Santos, Anjos, Simões, Rodrigues, \& Pereira, 2014; Santos et al., 2012).

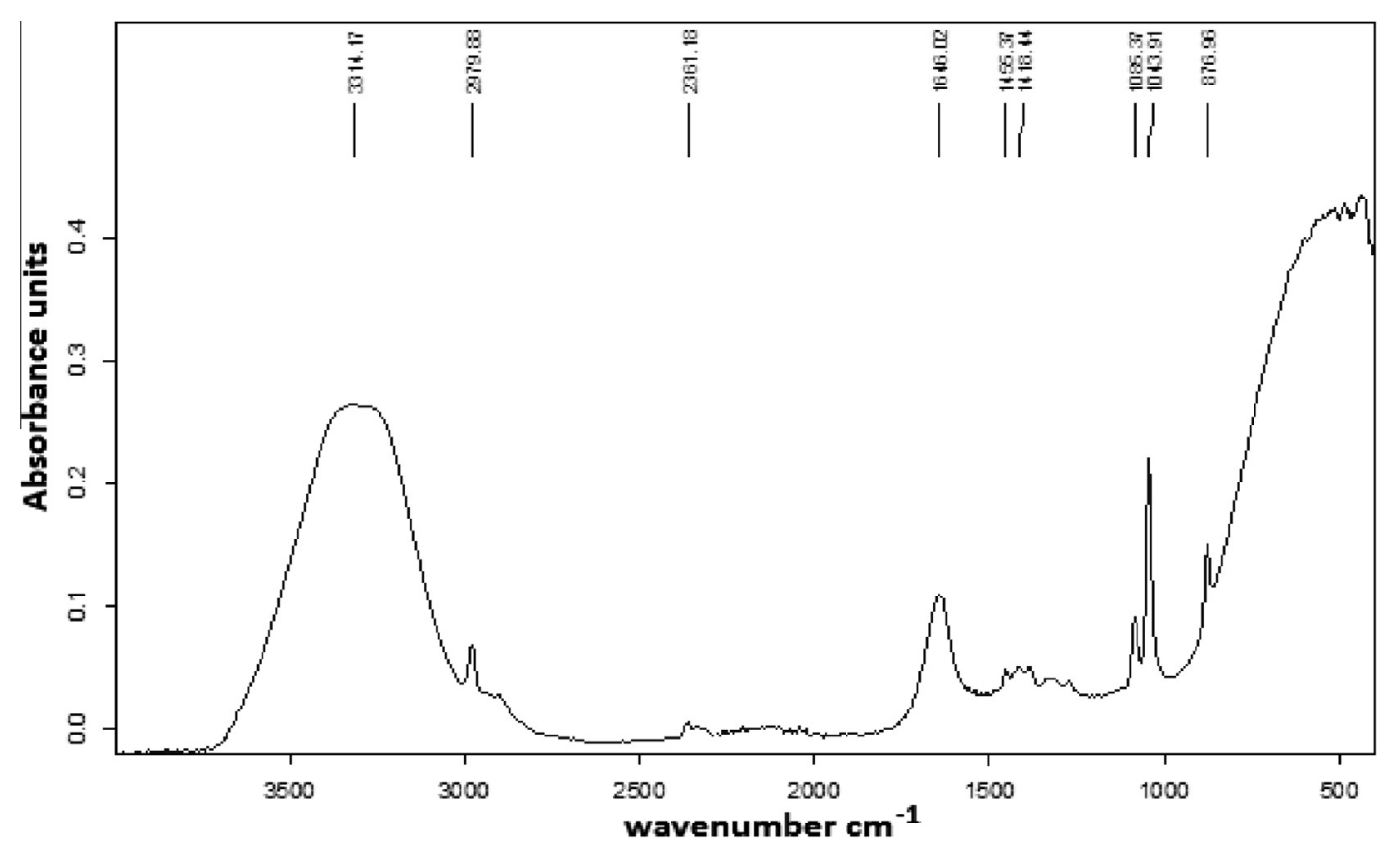

Fig. 1. Average ATR spectrum of wine spirit and grape marc spirit. 


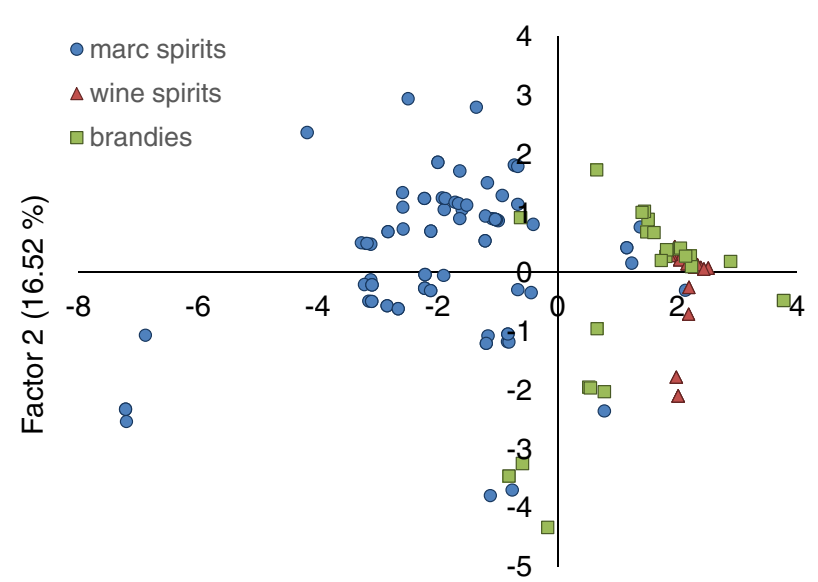

Fig. 2. PCA representation of loadings of all grape-derived spirits and for all measured determinations.

All models were calculated having into account the better values for coefficient of determination $\left(r^{2}\right)$, root mean square error of cross-validation (RMSECV), ratios of performance to deviation (RPD) for cross-validation and $r^{2}$, root mean square error of prediction (RMSEP) and RPD for test-set validation (Workman \& Weyer, 2007).

\section{Results and discussion}

\subsection{Sample selection}

From the sample group of 160 grape derived spirits, some of them were not taken into consideration for the model development because they presented concentrations below the quantification limit. As such, the sample number for each analytical determination was:
- Methanol - 166 samples (marc spirits - 82, wine spirits - 58, brandies - 26);

- Alcoholic strength - 140 samples (marc spirits - 75, wine spirits - 46, brandies - 19);

- 1-Butanol and 1-propanol - 94 samples of each compound (marc spirits - 61, wine spirits - 18, brandies - 15);

- 2-Butanol - 52 samples (marc spirits - 46, wine spirits - 6);

- Ethyl acetate and acetaldehyde - 95 samples for each compound (marc spirits - 58, wine spirits -28 , brandies -9 );

- 2-Methyl-1-propanol - 99 samples (marc spirits - 68, wine spirits - 14 brandies - 17);

- $2+3$ Methyl-1-butanol - 83 samples (marc spirits - 64, wine spirits - 14, brandies - 5).

\subsection{Infrared spectra characterisation and analysis}

The spectra obtained for the different type of grape-derived spirits under analysis are very similar. The differences could be seen only in the height of some peaks and not in the spectral region or in the occurrence of different peaks for different samples. Given this, it was decided to represent only the average spectra in Fig. 1. All the spectrum analyses are characterised by bands between 1500 and $900 \mathrm{~cm}^{-1}$, which correspond to $\mathrm{C}-\mathrm{C}$ and $\mathrm{C}-\mathrm{O}$ vibrations in volatile compounds of the beverages. The small peak at $1456 \mathrm{~cm}^{-1}$ corresponds to $\mathrm{C}-\mathrm{OH}$ bending deformation.

ATR spectrum of grape-derived spirit shows representative peaks at 3314 and $1646 \mathrm{~cm}^{-1}$ that are assigned to water, respectively to $\mathrm{OH}$-stretching and to OH-bending (Shurvell, 2001).

The peak at $1646 \mathrm{~cm}^{-1}$ represented by the $\mathrm{O}-\mathrm{H}$ deformation could be important in the alcohol compounds identification, so in some proposed models this region is included. Nevertheless, before the construction of the final model, tests were performed including the spectral region of $3314 \mathrm{~cm}^{-1}$ and the model becomes less accurate.

Table 1

Statistics of the sample sets for alcohol strength, methanol, fusel alcohols, ethyl acetate and acetaldehyde quantification in grape derived spirits.

\begin{tabular}{|c|c|c|c|c|c|c|}
\hline Analytical determination & & Number of samples & Mean $\pm \sigma$ & Min-max & Coefficient of variation & $\mathrm{LOQ}^{\mathrm{a}}$ \\
\hline Alcohol strength (\%) & $\begin{array}{l}\text { Set } 1+2 \\
\text { Set } 1 \\
\text { Set } 2\end{array}$ & $\begin{array}{l}140 \\
70 \\
70\end{array}$ & $\begin{array}{l}38.7 \pm 2.2 \\
38.5 \pm 2.2 \\
38.9 \pm 2.3\end{array}$ & $\begin{array}{l}34.3-45.8 \\
34.3-45.4 \\
35.9-45.8\end{array}$ & $\begin{array}{l}5.7 \\
5.6 \\
5.9\end{array}$ & - \\
\hline Methanol (g/hL P.A.) & $\begin{array}{l}\text { Set } 1+2 \\
\text { Set } 1 \\
\text { Set } 2\end{array}$ & $\begin{array}{l}166 \\
83 \\
83\end{array}$ & $\begin{array}{l}468 \pm 417 \\
440 \pm 408 \\
495 \pm 426\end{array}$ & $\begin{array}{l}30-2227 \\
30-2227 \\
52-2180\end{array}$ & $\begin{array}{l}89.0 \\
93.0 \\
86.0\end{array}$ & 3.51 \\
\hline 1-Butanol (g/hL P.A.) & $\begin{array}{l}\text { Set } 1+2 \\
\text { Set } 1 \\
\text { Set } 2\end{array}$ & $\begin{array}{l}94 \\
45 \\
49\end{array}$ & $\begin{array}{l}2.09 \pm 0.52 \\
2.08 \pm 0.53 \\
2.10 \pm 0.51\end{array}$ & $\begin{array}{l}1.10-3.02 \\
1.09-3.02 \\
1.12-2.91\end{array}$ & $\begin{array}{l}24.8 \\
25.4 \\
24.5\end{array}$ & 0.18 \\
\hline 1-Propanol (g/hL P.A.) & $\begin{array}{l}\text { Set } 1+2 \\
\text { Set } 1 \\
\text { Set } 2\end{array}$ & $\begin{array}{l}94 \\
45 \\
49\end{array}$ & $\begin{array}{l}40.4 \pm 12.8 \\
40.8 \pm 12.8 \\
40.0 \pm 12.9\end{array}$ & $\begin{array}{l}22.5-79.4 \\
22.5-77.8 \\
24.9-79.4\end{array}$ & $\begin{array}{l}31.6 \\
31.2 \\
32.2\end{array}$ & 0.64 \\
\hline 2-Butanol (g/hL P.A.) & Set $1+2$ & 52 & $7.36 \pm 5.31$ & $1.24-23.3$ & 72.2 & 1.11 \\
\hline Ethyl acetate (g/hL P.A.) & $\begin{array}{l}\text { Set } 1+2 \\
\text { Set } 1 \\
\text { Set } 2\end{array}$ & $\begin{array}{l}95 \\
48 \\
47\end{array}$ & $\begin{array}{l}191 \pm 143 \\
199 \pm 144 \\
183 \pm 143\end{array}$ & $\begin{array}{l}10.9-500 \\
11.8-496 \\
10.9-500\end{array}$ & $\begin{array}{l}74.7 \\
71.9 \\
78.3\end{array}$ & 1.18 \\
\hline Acetaldehyde (g/hL P.A.) & $\begin{array}{l}\text { Set } 1+2 \\
\text { Set } 1 \\
\text { Set } 2\end{array}$ & $\begin{array}{l}95 \\
47 \\
48\end{array}$ & $\begin{array}{r}115 \pm 78.2 \\
119.7 \pm 78.3 \\
109 \pm 78.8\end{array}$ & $\begin{array}{l}13.6-261 \\
17.5-261 \\
13.6-254\end{array}$ & $\begin{array}{l}68.3 \\
65.4 \\
71.9\end{array}$ & 4.92 \\
\hline 2-Methyl-1-propanol (g/hL P.A.) & $\begin{array}{l}\text { Set } 1+2 \\
\text { Set } 1 \\
\text { Set } 2\end{array}$ & $\begin{array}{l}99 \\
48 \\
51\end{array}$ & $\begin{array}{l}67.5 \pm 17.3 \\
66.7 \pm 18.2 \\
68.1 \pm 16.7\end{array}$ & $\begin{array}{l}34.9-100 \\
36.8-100 \\
34.9-100\end{array}$ & $\begin{array}{l}25.7 \\
27.2 \\
24.5\end{array}$ & 0.60 \\
\hline 2 + 3-Methyl-1-butanol (g/hL P.A.) & $\begin{array}{l}\text { Set } 1+2 \\
\text { Set } 1 \\
\text { Set } 2\end{array}$ & $\begin{array}{l}83 \\
41 \\
42\end{array}$ & $\begin{array}{l}217 \pm 44.0 \\
220 \pm 44.0 \\
213 \pm 45.0\end{array}$ & $\begin{array}{l}127-271 \\
127-271 \\
141-268\end{array}$ & $\begin{array}{l}20.0 \\
20.0 \\
21.0\end{array}$ & 0.35 \\
\hline
\end{tabular}

${ }^{\text {a }}$ LOQ - limit of quantification limit from Luís et al. (2011). 
Table 2

Cross-validation and validation set results of the calculated models obtained for different determinations.

\begin{tabular}{|c|c|c|c|c|c|c|c|c|c|c|c|c|}
\hline & \multirow[t]{2}{*}{ Spectral range $\left(\mathrm{cm}^{-1}\right)$} & \multirow[t]{2}{*}{ Pre-process } & \multicolumn{6}{|c|}{ Cross-validation } & \multicolumn{4}{|c|}{ Validation set } \\
\hline & & & $\mathrm{Rk}$ & Data set & $r^{2}$ & RMSECV & RPD & Bias & Data set & $r^{2}$ & RMSEP & RPD \\
\hline Methanol content (g/hL P.A.) & 1607-977 & MSC & $\begin{array}{l}6 \\
6 \\
7\end{array}$ & $\begin{array}{l}\text { Set } 1 \\
\text { Set } 2 \\
\text { Set } 1+2\end{array}$ & $\begin{array}{l}99.2 \\
99.3 \\
99.4\end{array}$ & $\begin{array}{l}36.7 \\
34.8 \\
32.4\end{array}$ & $\begin{array}{l}11.1 \\
12.1 \\
12.8\end{array}$ & $\begin{array}{r}0.556 \\
-0.795 \\
-0.439\end{array}$ & $\begin{array}{l}\text { Set } 2 \\
\text { Set } 1\end{array}$ & $\begin{array}{l}99.3 \\
99.3\end{array}$ & $\begin{array}{l}36.4 \\
34.7\end{array}$ & $\begin{array}{l}11.7 \\
11.9\end{array}$ \\
\hline Alcohol strength (\%) & $3057-2864+2236-1920+1292-663$ & 1stDer & $\begin{array}{l}2 \\
3 \\
2\end{array}$ & $\begin{array}{l}\text { Set } 1 \\
\text { Set } 2 \\
\text { Set } 1+2\end{array}$ & $\begin{array}{l}96.3 \\
97.3 \\
97.2\end{array}$ & $\begin{array}{l}0.44 \\
0.35 \\
0.37\end{array}$ & $\begin{array}{l}5.2 \\
6.1 \\
6.0\end{array}$ & $\begin{array}{r}-0.013 \\
0.001 \\
0.008\end{array}$ & $\begin{array}{l}\text { Set } 2 \\
\text { Set } 1\end{array}$ & $\begin{array}{l}97.1 \\
97.0\end{array}$ & $\begin{array}{l}0.36 \\
0.40\end{array}$ & $\begin{array}{l}5.9 \\
5.8\end{array}$ \\
\hline 1-Butanol (g/hL P.A.) & $3998-3638+1839-758$ & 1 stDer + MSC & $\begin{array}{l}7 \\
9 \\
7\end{array}$ & $\begin{array}{l}\text { Set } 1 \\
\text { Set } 2 \\
\text { Set } 1+2\end{array}$ & $\begin{array}{l}94.2 \\
96.8 \\
96.8\end{array}$ & $\begin{array}{l}0.13 \\
0.092 \\
0.092\end{array}$ & $\begin{array}{l}4.2 \\
5.6 \\
5.6\end{array}$ & $\begin{array}{r}0.002 \\
0.006 \\
-0.001\end{array}$ & $\begin{array}{l}\text { Set } 2 \\
\text { Set } 1\end{array}$ & $\begin{array}{l}93.9 \\
96.6\end{array}$ & $\begin{array}{l}0.126 \\
0.095\end{array}$ & $\begin{array}{l}4.1 \\
5.5\end{array}$ \\
\hline 2-Butanol (g/hL P.A.) & $3100-2495+1283-681$ & 1stDer+MSC & 5 & Set $1+2$ & 91.0 & 1.58 & 3.4 & 0.037 & & & & \\
\hline 1-Propanol (g/hL P.A.) & $2450-2198+1839-758$ & 1stDer + SLS & $\begin{array}{l}8 \\
7 \\
7\end{array}$ & $\begin{array}{l}\text { Set } 1 \\
\text { Set } 2 \\
\text { Set } 1+2\end{array}$ & $\begin{array}{l}96.1 \\
94.9 \\
97.4\end{array}$ & $\begin{array}{l}2.04 \\
2.29 \\
1.65\end{array}$ & $\begin{array}{l}5.1 \\
4.4 \\
6.2\end{array}$ & $\begin{array}{r}0.061 \\
0.140 \\
-0.008\end{array}$ & $\begin{array}{l}\text { Set } 2 \\
\text { Set } 1\end{array}$ & $\begin{array}{l}94.9 \\
97.2\end{array}$ & $\begin{array}{l}2.27 \\
1.72\end{array}$ & $\begin{array}{l}4.4 \\
6.1\end{array}$ \\
\hline Ethyl acetate (g/hL P.A.) & $2919-2558+1839-1118$ & SLS & $\begin{array}{l}5 \\
7 \\
7\end{array}$ & $\begin{array}{l}\text { Set } 1 \\
\text { Set } 2 \\
\text { Set } 1+2\end{array}$ & $\begin{array}{l}92.1 \\
90.4 \\
97.1\end{array}$ & $\begin{array}{l}40.0 \\
43.9 \\
24.3\end{array}$ & $\begin{array}{l}3.6 \\
3.3 \\
5.9\end{array}$ & $\begin{array}{r}1.160 \\
5.280 \\
-0.503\end{array}$ & $\begin{array}{l}\text { Set } 2 \\
\text { Set } 1\end{array}$ & $\begin{array}{l}96.2 \\
96.2\end{array}$ & $\begin{array}{l}27.6 \\
27.6\end{array}$ & $\begin{array}{l}5.3 \\
5.3\end{array}$ \\
\hline Acetaldehyde (g/hL P.A.) & $3998-3638+1839-758$ & MSC & $\begin{array}{l}8 \\
7 \\
8\end{array}$ & $\begin{array}{l}\text { Set } 1 \\
\text { Set } 2 \\
\text { Set } 1+2\end{array}$ & $\begin{array}{l}97.9 \\
96.8 \\
98.2\end{array}$ & $\begin{array}{l}11.0 \\
13.7 \\
10.4\end{array}$ & $\begin{array}{l}6.9 \\
5.6 \\
7.5\end{array}$ & $\begin{array}{r}-0.340 \\
0.921 \\
-0.491\end{array}$ & $\begin{array}{l}\text { Set } 2 \\
\text { Set } 1\end{array}$ & $\begin{array}{l}97.8 \\
98.2\end{array}$ & $\begin{array}{l}11.2 \\
10.4\end{array}$ & $\begin{array}{l}6.8 \\
7.5\end{array}$ \\
\hline 2-Methyl-1-propanol (g/hL P.A.) & $3998-3638+2919-758$ & MSC & $\begin{array}{l}8 \\
4 \\
8\end{array}$ & $\begin{array}{l}\text { Set } 1 \\
\text { Set } 2 \\
\text { Set } 1+2\end{array}$ & $\begin{array}{l}89.0 \\
90.2 \\
95.7\end{array}$ & $\begin{array}{l}6.01 \\
5.09 \\
3.56\end{array}$ & $\begin{array}{l}3.0 \\
3.2 \\
4.9\end{array}$ & $\begin{array}{r}0.479 \\
-0.449 \\
-0.220\end{array}$ & $\begin{array}{l}\text { Set } 2 \\
\text { Set } 1\end{array}$ & $\begin{array}{l}96.4 \\
87.9\end{array}$ & $\begin{array}{l}3.12 \\
6.24\end{array}$ & $\begin{array}{l}5.3 \\
2.9\end{array}$ \\
\hline 2 + 3-Methyl-1-butanol (g/hL P.A.) & $3998-3638+2919-758$ & 2ndDer & $\begin{array}{l}8 \\
8 \\
9\end{array}$ & $\begin{array}{l}\text { Set } 1 \\
\text { Set } 2 \\
\text { Set } 1+2\end{array}$ & $\begin{array}{l}86.4 \\
88.1 \\
94.1\end{array}$ & $\begin{array}{l}15.7 \\
15.4 \\
10.7\end{array}$ & $\begin{array}{l}2.7 \\
2.9 \\
4.1\end{array}$ & $\begin{array}{r}-1.470 \\
0.497 \\
-0.534\end{array}$ & $\begin{array}{l}\text { Set } 2 \\
\text { Set } 1\end{array}$ & $\begin{array}{l}87.5 \\
89.4\end{array}$ & $\begin{array}{l}15.9 \\
14.0\end{array}$ & $\begin{array}{l}2.9 \\
3.1\end{array}$ \\
\hline
\end{tabular}

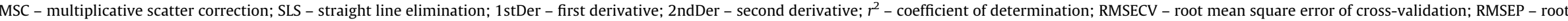
mean square error of prediction; RPD - ratios of performance to deviation; Bias - mean value of deviation, also called systematic error; Rk - rank. 
The spectra hereby described were similar to those reported in the literature (Nagarajan et al., 2006) for six commercial alcoholic beverages (brandy, vodka, gin, rum, whisky and red wine).

\subsection{Calibration model development}

For developing the calibration models for the different analytical determinations, the entire infrared spectral region (4000$400 \mathrm{~cm}^{-1}$ ) was used for spectral acquisition since the PCA analyses of the spectra did not identify any redundant spectra for rejection. However, it is important to refer that the absorption band between 3600 and $3100 \mathrm{~cm}^{-1}$ was not taken into account because there was a considerable interference of samples' water. The same occurs regarding the regions between 600 and $400 \mathrm{~cm}^{-1}$, where high absorption of the incident light by components of the system and water is noticeable. Therefore the spectral region used to perform the calibration model was the region between $4000-3600 \mathrm{~cm}^{-1}+3100-600 \mathrm{~cm}^{-1}$.

The most accurate model was selected according to the analyses of all error parameters, namely: higher RPD; lower standard error of prediction of the test-set values predicted by the calibration model and the standard deviation of the corresponding reference data (RMSECV - root mean square error of cross-validation and RMSEP - root mean square error of prediction); and lower rank used in the prediction.

In this study, alcoholic strength, methanol, 1-butanol, 1-propanol, 2-butanol, ethyl acetate, acetaldehyde, 2-methyl-1propanol and $2+3$ methyl-1-butanol determinations of the grape-derived spirits presented a broad range of values (Fig. 2 and Table 1), suggesting a good data scattering.

The values of methanol in the spirit samples were spread through all the ranges up to the legal limits of $200 \mathrm{~g} / \mathrm{hL}$ P.A. for wine spirits, and $1000 \mathrm{~g} / \mathrm{hL}$ P.A. for grape-derived spirits. In the case of grape marc spirit, a few samples exceeded the legal methanol limit. This fact is important in order to increase model accuracy for the extremes of the calibration zone. In spite of this, a model was analysed without these values and the obtained parameters were very similar, reason by which the authors decided to present the model comprising all available values.

In a first step PLS calibration models were performed separately for two groups: marc spirits and wine spirits. However, the models are very similar, but with lower accuracy (data not shown), of those obtained with all data. Consequently, it was decided to show only the final model with marc spirits and wine spirits together, which present a higher accuracy and also because for a quality control laboratory it is easier to use only one model than two.

As such, PLS was used to develop the calibration model with a selected spectral range. Then, pre-treatments were applied in order to increase the performance of the predictive models. A different spectral range was selected for each compound analysed (Table 2). Thus, for methanol quantification the spectral range between 1607 and $977 \mathrm{~cm}^{-1}$ was selected; for alcoholic strength between $3057-2864+2236-1920+1292-663 \mathrm{~cm}^{-1}$; for 1-butanol between $3998-3638+1839-758 \mathrm{~cm}^{-1}$; for 1-propanol between $2450-2198+1839-758 \mathrm{~cm}^{-1}$; for 2-butanol between $3100-2495$ $+1283-681 \mathrm{~cm}^{-1}$; for ethyl acetate between $2919-2558+1839-$ $1118 \mathrm{~cm}^{-1}$; for acetaldehyde between $3998-3638+1839-758$ $\mathrm{cm}^{-1}$; for 2-methyl-1-propanol and 2+3-methyl-1-butanol between 3998-3638 + 2919-758 $\mathrm{cm}^{-1}$.

A similar region was used for methanol and ethyl acetate content evaluation in traditional fruit brandies from Romania using FTIR-ATR (Coldea et al., 2013).

In the ATR spectrum of grape-derived spirits a peak at $2979 \mathrm{~cm}^{-1}$ was observed, which is due to the $\mathrm{C}-\mathrm{H}$ deformation characteristics of the methanol compound. In this spectral region, there is also the asymmetric stretching band of the methyl group, not characteristic of methanol but, nevertheless, important for the absorbance of ethanol and other fusel alcohols.

According to Shurvell (2001) much-closed peaks at 1085 and $1043 \mathrm{~cm}^{-1}$ correspond to the $\mathrm{C}-\mathrm{O}$ stretch absorption bands. These bands are important regions for ethanol and methanol quantification, respectively.

The better model, for each analytical determination, obtained with the various pre-processing analysed of the raw spectral data obtained with the ATR based data regressed against their GC-FID determination is summarised in Table 2 for cross-validation and for validation set.

Each model was selected according to some criteria that were analysed carefully for our data set. First of all, it is important to state that the selected model is the one that does not present outliers, besides having a higher coefficient of determination for both sets, with a higher residual prediction deviation and lower root mean square error of cross-validation and prediction of the lower possible rank.

Regarding the bias analysis, the conclusion is similar. Moreover, the values observed for the selected pre-process seem not to be the better, but the other parameters are more relevant and confirm the selection of the model with a pre-process of multiplicative scatter correction.

Fig. 3 shows the representation FTIR-ATR PLSR data predicted with reference method determination for some measured parameter (methanol, alcoholic strength, 1-propanol, ethyl acetate) and spectral data for set $1+2$ for cross-validation. All analytical determinations have high correlation coefficient between the predicted and the determined content values, with a rank that varied between 2 and 8 , without outliers.

According to Workman and Weyer (2007), the RPD, that measures the ratio between the standard deviation of the reference data of the validation set and the standard error of prediction of a cross-validation or of the test set validation, must be superior than 2.5 for a good calibration.

In this particular case, the RPD for the validation of the FTIRATR PLSR model for different measured parameters varied from 12.1 for SET 2 for methanol to 2.7 for SET1 for 2 + 3-methyl-1butanol in cross-validation and from 11.9 for SET 2 for methanol to 2.9 for $2+3$-methyl-1-butanol and 2-metil-1-propanol in validation SET (Table 2).

The scale, applied to broadly categorise PLS-R models by their fitness, was useful for our data set, which contained an unwieldy number of models with a wide range of performances.

Table 2 represents the better model obtained from the selected region, for all pre-processes analysed for each parameter and Fig. 3 represents the correlation curves performed for set $1+2$ for same analysed parameters.

The best model found in this work with FTIR-ATR is for methanol quantification with a RPD of $12.8\left(r^{2}=99.4\right)$. Different authors have also found good values for methanol quantification values with other similar beverages. Indeed, Yucesoy and Ozen (2013) reported RPD values of $8.4\left(r^{2}=98 \%\right)$ for methanol determination in Raki beverages using mid-IR spectral data samples. Coldea et al. (2013) obtained good models between FTIR and GC-FID analyses for methanol quantification in fruit brandies made by traditional technology in Romania. Lachenmeier (2007), who analysed spirit drinks and beer and compared the reference methods with the spectral results from FTIR in combination with multivariate data analysis, obtained a correlation model with an $r^{2}=99.7 \%$ for cross-validation and an $r^{2}=98.1 \%$ for Test-set validation. In addition, these authors analysed other volatile compounds that are also focused in our study, namely ethyl acetate, propanol-1, 2-methyl-1-propanol and 2-/ 3-methyl-1-butanol, with good coefficients of correlation: between 

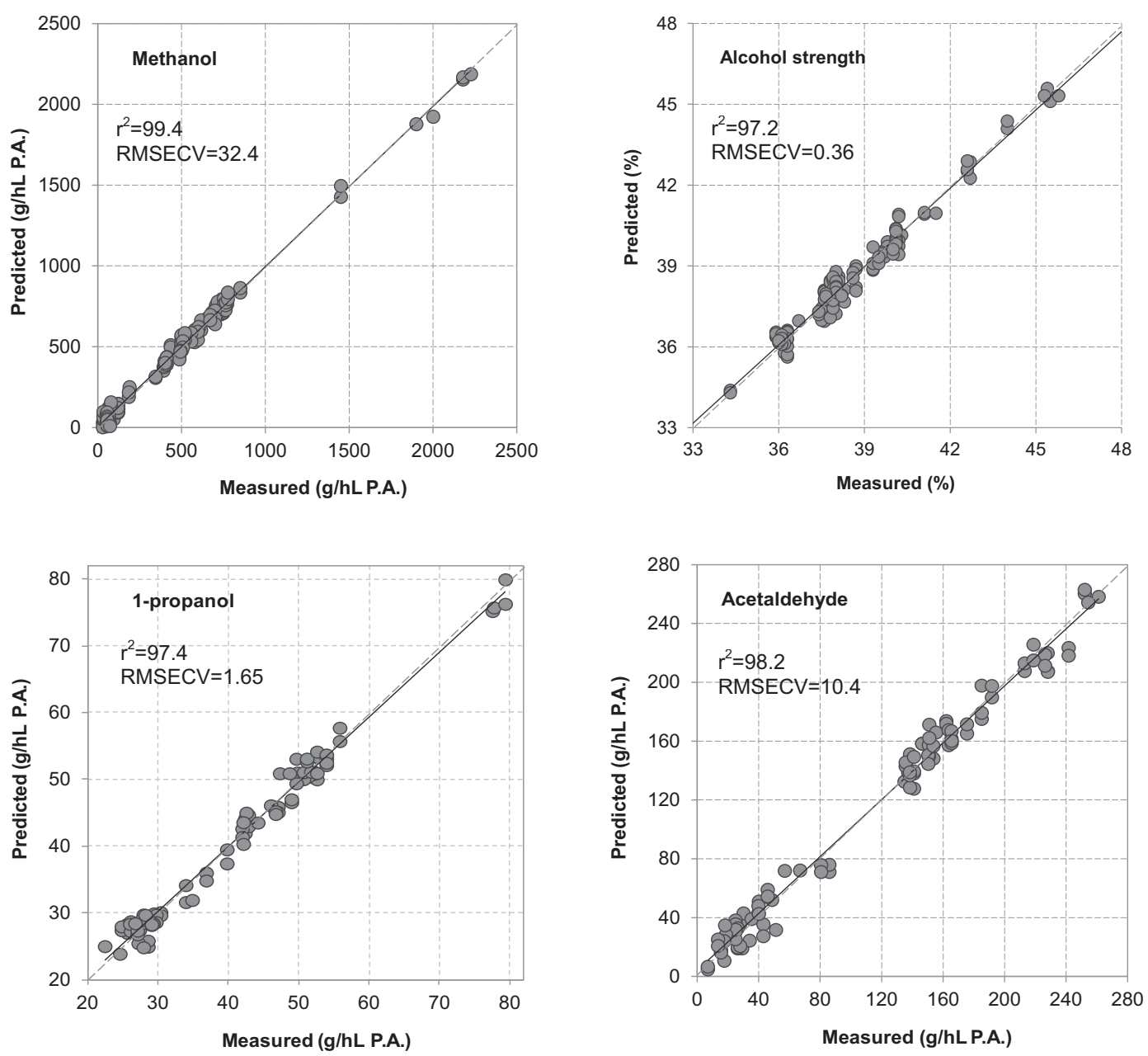

Fig. 3. Correlation curves of different analysed parameter concentration in derived-spirit samples from the model obtained with set $1+2$.

$99.8 \%$ and $94.0 \%$ for cross-validation and from $98.1 \%$ to $90.1 \%$ for test set validation.

Regarding the acetaldehyde concentration this work provides a very good calibration model with $r^{2}=98.2 \%$ and a RPD of 7.5.

Our research reconfirms the applicability of IR spectroscopy on the evaluation of the methanol, ethanol, acetaldehyde and fusel alcohols contents of alcoholic beverage and demonstrates the ability of the FTIR-ATR technique to measure those parameters in grape-derived spirits.

\section{Conclusion}

According to the developed and selected models, it can be considered that the method has an acceptable accuracy for the purpose of screening analysis for determining the methanol, alcoholic strength, acetaldehyde and fusel alcohols content in grape-derived spirits. This technique, which may be adopted on the routine analysis easily, gives a higher value of the residual prediction deviation and coefficient of determination. Additionally, this technique has the advantage of requiring a reduced sampling path length, besides being simple, fast and more cost-effective for the control of these compounds in grape derived spirit.

Nevertheless, the calibration model obtained for 2-butanol has an $r^{2}$ of $91 \%$ and a RPD equal to 3.4. Therefore, more studies are required in order to increase the consistency of these results, hence it was not possible to apply the same methodology (Set 1, Set 2 and Set $1+$ Set 2) for this compound.

Also, it would be interesting to calibrate further qualityrelevant parameters in grape-derived spirits.

\section{Acknowledgments}

The authors thank the technical support of Amélia Soares, Deolinda Mota and Otília Cerveira and the support of Centro de Estudos Florestais, a research unit funded by FCT (PEst-OE/AGR/ UI0239-2014) and Instituto de Ciências Agrárias e Ambientais Mediterrânicas, a research unit funded by FCT (PEst-OE/AGR/ UI0115/2014).

The authors also thank to Centro de Biotecnologia de Plantas da Beira Interior for the FTIR-ATR equipment and software OPUS availability.

\section{References}

Anjos, O., Campos, M. G., Ruiz, P. C., \& Antunes, P. (2015). Application of FTIR-ATR spectroscopy to the quantification of sugar in honey. Food Chemistry, 169, 218-223. http://dx.doi.org/10.1016/j.foodchem.2014.07.138.

Bauer, R., Nieuwoudt, H., Bauer, F. F., Kossmann, J., Koch, K. R., \& Esbensen, K. H. (2008). FTIR spectroscopy for grape and wine analysis. Analytical Chemistry, 80 (5), 1371-1379. http://dx.doi.org/10.1021/ac086051c.

Caldeira, I., Anjos, O., Portal, V., Belchior, a. P., \& Canas, S. (2010). Sensory and chemical modifications of wine-brandy aged with chestnut and oak wood fragments in comparison to wooden barrels. Analytica Chimica Acta, 660(1-2), 43-52. http://dx.doi.org/10.1016/j.aca.2009.10.059. 
Cocciardi, R. A., Ismail, A. A., \& Sedman, J. (2005). Investigation of the potential utility of single-bounce attenuated total reflectance Fourier transform infrared spectroscopy in the analysis of distilled liquors and wines. Journal of Agricultural and Food Chemistry, 53(8), 2803-2809. http://dx.doi.org/10.1021/jf048663d.

Coldea, T. E., Socaciu, C., Fetea, F., Ranga, F., Pop, R. M., \& Florea, M. (2013). Rapid quantitative analysis of ethanol and prediction of methanol content in traditional fruit brandies from Romania, using FTIR spectroscopy and chemometrics. Notulae Botanicae Horti Agrobotanici Cluj-Napoca, 41(1), 143-149.

Fotakis, C., Kokkotou, K., Zoumpoulakis, P., \& Zervou, M. (2013). NMR metabolite fingerprinting in grape derived products: An overview. Food Research International, 54(1), 1184-1194. http://dx.doi.org/10.1016/j.foodres.2013. 03.032.

Gouvinhas, I., de Almeida, J. M. M. M., Carvalho, T., Machado, N., \& Barros, A. I. R. N. A. (2015). Discrimination and characterisation of extra virgin olive oils from three cultivars in different maturation stages using Fourier transform infrared spectroscopy in tandem with chemometrics. Food Chemistry, 174, 226-232. http://dx.doi.org/10.1016/j.foodchem.2014.11.037.

Hantson, P. E. (2006). Acute methanol intoxication: Physiopathology, prognosis and treatment. Bulletin et Memoires de l'Academie Royale de Medecine de Belgique, 161 (6), 425-434. discussion 434-436.

Lachenmeier, D. W. (2007). Rapid quality control of spirit drinks and beer using multivariate data analysis of Fourier transform infrared spectra. Food Chemistry. 101(2), 825-832. http://dx.doi.org/10.1016/j.foodchem.2005.12.032.

Lachenmeier, D. W., Richling, E., López, M. G., Frank, W., \& Schreier, P. (2005) Multivariate analysis of FTIR and ion chromatographic data for the quality control of tequila. Journal of Agricultural and Food Chemistry, 53(6), 2151-2157. http://dx.doi.org/10.1021/jf048637f.

Linderborg, K., Joly, J. P., Visapää, J. P., \& Salaspuro, M. (2008). Potential mechanism for Calvados-related oesophageal cancer. Food and Chemical Toxicology, 46(2) 476-479. http://dx.doi.org/10.1016/j.fct.2007.08.019.

Luís, A., Mota, D., Anjos, O., \& Caldeira, I. (2011). Single-laboratory validation of determination of acetaldehyde, ethyl acetate, methanol and fusel alcohols in wine spirits, brandies and grape marc spirits using GC-FID. Ciência e Técnica Vitivinícola, 26(2), 69-76.

Nagarajan, R., Gupta, a., Mehrotra, R., \& Bajaj, M. M. (2006). Quantitative analysis of alcohol, sugar, and tartaric acid in alcoholic beverages using attenuated total reflectance spectroscopy. Journal of Automated Methods \& Management in Chemistry, 2006, 45102. http://dx.doi.org/10.1155/JAMMC/2006/45102.

Nieuwoudt, H. H., Prior, B. A., Pretorius, I. S., Manley, M., \& Bauer, F. F. (2004). Principal component analysis applied to Fourier transform infrared spectroscopy for the design of calibration sets for glycerol prediction models in wine and for the detection and classification of outlier samples. Journal of Agricultural and Food Chemistry, 52(12), 3726-3735. http://dx.doi.org/10.1021/ jf035431q.

Nykänen, L., \& Nykänen, I. (1991). Distilled beverages. In H. Maarse (Ed.), Volatile Compounds in Food and Beverages (pp. 547-580). New York: Marcell Dekker Inc.
OIV. (2014). Compendium of international methods of analysis of spirituous beverages of vitivinicultural origin (p. 225). Paris.

Palma, M. (2002). Application of FT-IR spectroscopy to the characterisation and classification of wines, brandies and other distilled drinks. Talanta, 58(2), 265-271. http://dx.doi.org/10.1016/S0039-9140(02)00244-8.

Pontes, M. J. C., Santos, S. R. B., Araújo, M. C. U., Almeida, L. F., Lima, R. A. C., Gaião, E. N., \& Souto, U. T. C. P. (2006). Classification of distilled alcoholic beverages and verification of adulteration by near infrared spectrometry. Food Research International, 39(2), 182-189. http://dx.doi.org/10.1016/j.foodres.2005.07.005.

Quady, K., Quady, Andrew K., \& Guymon, J. F. (1973). Relation of maturity, acidity, and growing region of 'thompson seedless' and 'french colombard' grapes to wine aroma and quality of brandy distillate. American Journal of Enology and Viticulture, 24(4), 166-175.

Rinnan, Åsmund., van den Berg, F., \& Engelsen, S. B. (2009). Review of the most common pre-processing techniques for near-infrared spectra. Trends in Analytical Chemistry, 28(10), 1201-1222. http://dx.doi.org/10.1016/j.trac.2009. 07.007.

Santos, A., Alves, A., Simões, R., Pereira, H., Rodrigues, J., \& Schwanninger, M. (2012). Estimation of wood basic density of Acacia melanoxylon (R. Br.) by near infrared spectroscopy. Journal of Near Infrared Spectroscopy, 20(2), 267. http://dx.doi.org/ 10.1255 /jnirs.986.

Santos, A., Anjos, O., Simões, R., Rodrigues, J., \& Pereira, H. (2014). Com Kappa number prediction of Acacia melanoxylon unbleached kraft pulps using NIRPLSR models with a narrow interval of variation. Bioresources, 9(4), 6735-6744.

Shurvell, H. F. (2001). Handbook of vibrational spectroscopy. New York, NY, USA: JohnWiley \& Sons, Ed.

Siu, M. T., Shapiro, A. M., Wiley, M. J., \& Wells, P. G. (2013). A role for glutathione, independent of oxidative stress, in the developmental toxicity of methanol. Toxicology and Applied Pharmacology, 273(3), 508-515. http://dx.doi.org/ 10.1016/j.taap.2013.09.020.

Swiegers, J. H., Bartowsky, E. J., Henschke, P. A., \& Pretorius, I. S. (2005). Yeast and bacterial modulation of wine aroma and flavour. Australian Journal of Grape and Wine Research, 11(2), 139-173. http://dx.doi.org/10.1111/j.1755-0238.2005. tb00285.x.

Tarantilis, P. A., Troianou, V. E., Pappas, C. S., Kotseridis, Y. S., \& Polissiou, M. G. (2008). Differentiation of Greek red wines on the basis of grape variety using attenuated total reflectance Fourier transform infrared spectroscopy. Food Chemistry, 111(1), 192-196. http://dx.doi.org/10.1016/j.foodchem.2008.03.020.

Wiberg, G. S., Trenholm, H. L., \& Coldwell, B. B. (1970). Increased ethanol toxicity in old rats: Changes in LD50, in vivo and in vitro metabolism, and liver alcohol dehydrogenase activity. Toxicology and Applied Pharmacology, 16(3), 718-727. http://dx.doi.org/10.1016/0041-008X(70)90077-3.

Workman, J. J., \& Weyer, L. (2007). Practical guide to interpretive near-infrared spectroscopy. C. Press, Ed., Taylor \& F.

Yucesoy, D., \& Ozen, B. (2013). Authentication of a Turkish traditional aniseed flavoured distilled spirit, raki. Food Chemistry, 141(2), 1461-1465. http://dx.doi. org/10.1016/j.foodchem.2013.04.015. 